\title{
Isolation and Characterization of Midgut Lectin From Aedes aegypti (L.) (Diptera: Culicidae)
}

\author{
Tahany Hassan Ayaad ${ }^{1,2 *}$, Rasha Khalifah Al- Akeel ${ }^{1}$ and Ebtisam Olayan ${ }^{1}$ \\ ${ }^{I}$ Zoology Department; College of Science; King Saud University; Riyadh; Saudi Arabia. ${ }^{2}$ Entomology Department; \\ College of Science; Cairo University; Giza - Egypt
}

\begin{abstract}
The present investigation deals with the isolation and characterization of a lectin from Aedes aegypti (Ae aegypti) female mid gut extract that agglutinates various mammalian red blood cells (RBCs) such as human three groups A, $B$, and $\mathrm{O}\left(\mathrm{RH}^{+}\right)$, mouse, rat, guinea-pig, sheep and goat erythrocytes. The highest activity of both crude and isolated mid gut lectins were detected against sheep RBCs. Using $\left(\mathrm{NH}_{4}\right)_{2} \mathrm{SO}_{4}$ fractionation, ion-exchange and mannoseCNBr-Sepharose $6 B$ affinity chromatography techniques, Ae. aegypti midgut lectin (Aelec) was purified to homogeneity. Isoelectric focusing (IEF) and reducing SDS/PAGE revealed that the isolated mid gut lectin had isoelectric point (PI) of 5.90, and subunits approximate molecular weights of 35.50 and 27.35 KDa. The hemagglutination (HA) of lectins were $\mathrm{Ca}^{2+}$ - independent and heat-resistant. The sugar specificity of the purified Aelec was strongly inhibited by $D(+)$-mannose and raffinose, followed by $D(+)$ glucose. $N$-acetyl-D-manosamine and $N$-acetyl-D-glucosamine were moderate inhibitors. None of the lectins were inhibited by the disaccharides such as galactose, lactose, trehalose (IC50 up to $200 \mathrm{mM}$ or fetuin up to 1\%) but the glycosubstances mucin and laminarin were strong inhibitors up to very low concentrations $(0.030-0.003 \%)$.
\end{abstract}

Key words: Lectin, purification, characterization, hemagglutination, Aedes aegypti, mosquitoes

\section{INTRODUCTION}

Vector-borne diseases affect two-thirds of the world's population and kill millions annually (Gubler 1998). Different mosquito vectors spread all over the Kingdom of Saudi Arabia (Abdoon and Ibrahim 2005; Al-Khreji 2005; Ahmed et al. 2011).

In Saudi Arabia, the mosquitoe Ae aegypti is involved in the transmission of Dengue and yellow fever (Fakeeh and Zaki 2003; Ayyub et al. 2006; Khan et al. 2008; Ahmed et al. 2014). The consequence of vector - borne diseases and their vectors, introduces the control strategies of insecticides to reduce vector populations and drugs to kill the pathogens. Over last few decades, both the vectors and parasites of mosquito-borne diseases have developed resistance against many commonly used pesticides and drugs, respectively. Lectins are a major constituent in the humoral immune mechanisms of the insects and the processes of self/non-self recognition (Gillespie et al. 1997; Kurata et al. 2006; Vasta et al. 2007). They are proteins that recognize specific carbohydrate structures, and thereby agglutinate the cells by binding to cell surface sugars, glycoproteins, and other glycoconjugates (Lis and Sharon 1998). They are usually structurally complex molecules with one or more carbohydrate-recognition domains and therefore,

*Author for correspondence: ayaad_tahany@hotmail.com 
of possible multiple binding sites (Gillespie et al. 1997; Dodd and Drickamer 2001).

One of the most important factors affecting the capacity of insects as vectors is the lectincarbohydrate interactions, which can mediate the infection of pathogens to the insect vectors; and their disruption that affect subsequent establishment within the vector (Volf et al. 2002).

Relatively few insect lectins have been isolated and characterized. Culicidae was isolated from Anopheles gambiae (Mohamed and Ingram 1994) and Anopheles stephensi (Chen and Billingsley 1999) and Ae aegypti (Ayaad 2008). Knowledge about lectin structure, function, and carbohydrate binding properties still need further investigations to clarify their role in the innate immune system of insects. Therefore, the present work aimed at the purification and partially characterization of lectin from female Ae aegypti as a step in the subsequent evaluation of its potential towards the biological activity suppression of this serious insect vector.

\section{MATERIAL AND METHODS}

\section{Insects}

A colony of Ae. aegypti was established as larvae collected from different localities in Jeddah, Saudi Arabia. The larvae were identified according to Mattingly and Knight (1956), kept in the laboratory till the adult emergence, and fed on the fish food $\left(\right.$ Tetramin $\left.^{\circledR}\right)$. Mosquitoes were reared at $25 \pm 2{ }^{\circ} \mathrm{C}$ and $60-70 \% \mathrm{RH}$ under 12:12h light: dark photoperiod. Adults were supplied with a damp cotton wool pad containing $10 \%$ sucrose solution and females were allowed to feed on Syrian hamster Mexricentus auratus (M. auratus).

\section{Sample Preparation}

Non-engorged females of Ae. Aegypti (7-10-dayold) were used in all the experiments. About 1000 females were dissected on a sterile glass slide and the midguts were taken out. The midguts were homogenized with a Teflon homogenizer in Eppendorf tubes on ice in PBS (pH 7.4). Samples were centrifuged at $3000 \mathrm{rpm}$ at $4^{\circ} \mathrm{C}$ for $5 \mathrm{~min}$ and the supernatants (referred as crude state of lectin) were collected for subsequent use.

\section{Isolation of Lectin}

\section{$\left(\mathrm{NH}_{4}\right)_{2} \mathrm{SO}_{4}$ fractionation}

Proteins of the crude lectin state were precipitated with stepwise increasing saturation percentages of
$\left(\mathrm{NH}_{4}\right)_{2} \mathrm{SO}_{4} \quad(30-80 \%)$. Precipitates showing positive haemagglutination (HA) (mainly from the 60-80\% saturation fractions) were pooled, redissolved in distilled water, and subsequently dialyzed against TBS/ $\mathrm{HCl}, \mathrm{pH} 7.4$ (containing 100 $\mathrm{mM} \mathrm{NaCl}$ ) at $4^{\circ} \mathrm{C}$ for $24 \mathrm{~h}$ with three changes against $500 \mathrm{ml}$ of the same buffer (Ayaad et al. 2009).

\section{Ion-exchange Chromatography.}

The dialyzed samples were centrifuged and the supernatants were subjected to ion exchange chromatography using a DEAE-cellulose (Bio$\mathrm{Rad})$ column $(1 \times 30 \mathrm{~cm})$ equilibrated with $\mathrm{TBS} / \mathrm{HCl}(\mathrm{pH} 7.4)$ and eluted by $\mathrm{NaCl}$ of stepwise increased concentration $(0.05-0.5 \mathrm{M})$ at a flow rate of $1.0 \mathrm{~mL} / \mathrm{min}$. The HA of the eluted protein fractions were estimated against sheep red blood cells (RBCs). Fractions corresponding to each peak showing positive agglutination activity were collected into one pool and dialyzed for an overnight against TBS (containing $50 \mathrm{mM} \mathrm{NaCl}$ ) at $4^{\circ} \mathrm{C}$ ) (Ingram and Molyneux 1990; Ayaad 2008; Ayaad et al. 2009).

\section{Affinity Chromatography}

Lectin was isolated at $4^{\circ} \mathrm{C}$ by one step affinity chromatography using a $\mathrm{CNBr}$-mannose-sepharose $6 \mathrm{~B}$ column $(1.5 \times 20 \mathrm{~cm})$ according to Komano et al. (1980), with slight modifications. Mannose (75 $\mathrm{mg}$, Sigma) was mixed with $3.0 \mathrm{mg}$ sepharose 6B into the column and equilibrated with $\mathrm{TBS} / \mathrm{HCl}$ $(\mathrm{pH} 7.4)$ at a flow rate of $1.0 \mathrm{~mL} / \mathrm{min}$. Two milliliters of the crude lectin, with total protein content of $\sim 1.2 \mathrm{mg} / \mathrm{mL}$, were two-fold diluted in TBS/Ca-Mg and slowly applied to the column. The column was extensively washed with TBS to which $0.5 \mathrm{M} \mathrm{NaCl}$ was added until the absorbance at $280 \mathrm{~nm}$ was almost zero. The bound material was eluted with $0.3 \mathrm{M}$ mannose solution in TBS. The collected fractions were dialyzed against TBS/Ca-Mg, then against deionized distilled $\mathrm{H} 2 \mathrm{O}$ as described by Miarons and Escudero (2000). Each fraction was tested for agglutination against sheep erythrocytes and positive fractions (exhibiting HA) were stored at $-70^{\circ} \mathrm{C}$ until used.

\section{Physicochemical Characterization of Lectin Protein Determination}

The protein concentrations of the crude plasma and the lectins isolated from either males or females were determined by the method of 
Bradford (1976). Bovine serum albumin was used for standard preparations.

\section{Molecular Weight Estimation by Sodium Dodecyl-Polyacrylamide Gel Electrophoresis (SDS/PAGE)}

SDS/PAGE was carried out by the method of Laemmli (1970). Proteins, either loaded directly or denatured with $1 \%$ SDS and $2 \% \quad 2$ mercaptoethanol by heating at $75^{\circ} \mathrm{C}$ for $15 \mathrm{~min}$ were loaded onto SDS slab gels containing 10\% acrylamide. After electrophoresis, gels were stained with freshly prepared silver nitrate for 15 min (Silver Quest Silver stain kit) according to Rabilloud (1990). For the determination of molecular weight, the gel was calibrated with the following marker proteins: feritin $(450 \mathrm{kDa})$, bovine serum albumin (BSA) $(68 \mathrm{kDa})$, ovalbumin (45 kDa), $\alpha$-chemotrypsinogen $(15 \mathrm{kDa})$, and cytochrome $c(12.5 \mathrm{kDa})(\mathrm{GmbH})$.

\section{Iso-electric focusing (IEF)}

The $\mathrm{pI}$ value of the lectin was evaluated with precast polyacrylamide gels (PhastGel, Pharmacia, Uppsala, Sweden) in the $\mathrm{pH}$ range 3.6-9.3 according to O'Farrel (1975). The gel was fixed for $20 \mathrm{~min}$ in sulphosalicylic acid containing trichloroacetic acid and then stained with Coomassie Blue R250. The $\mathrm{pH}$ gradient in the gels was determined from simultaneous runs performed with a wide-range iso-electric-focusing protein calibration kit (IEF MIX-Sigma, USA, $\mathrm{pH}$ 3.6-9.3) containing the following pI reference proteins: amyloglucosidase ( $\mathrm{pI}$ 3.6), trypsin inhibitor (pI 4.6), $\beta$-lactoglobulin A (pI 5.1), bovine carbonic anhydrase II (pI 5.9), human carbonic anhydrase I (pI 6.6), myoglobin (pI 6.8, 7.2), and trypsinogen (pI 9.3), L- lactate degydrogenase (pI 9.3), and trypsinogen (pI 9.3).

\section{Effect of Heating}

Aliquots $(25 \mu \mathrm{L})$ of semi-lyophilized crude or isolated lectin were kept at $4{ }^{\circ} \mathrm{C}$ or heated in a water bath for $1 \mathrm{~h}$ at a temperature gradient 10$100^{\circ} \mathrm{C}$. Tubes were loosely covered with small aluminum foil caps to reduce evaporation. HA were thereafter assessed against sheep RBCs (Ingram and Molyneux 1990; Ayaad 2008).

\section{Erythrocytes Preparation}

Sheep, goat, rabbit, Guinea-pig, mouse and rat blood was collected aseptically (VACSERA, Cairo, Egypt), each in an equal volume of heparin.
Human blood (A, B, O) $\left(\mathrm{RH}^{+}\right)$was obtained from Laboratories of Ministry of Health, Saudi Arabia. RBCs were separated, washed three times in phosphate buffer saline ( $\mathrm{pH} 7.2)$, centrifuged at $800 \mathrm{~g}$ for $15 \mathrm{~min}$ and then re-suspended at $2 \%$ (v/v) concentration in the same buffer containing $2 \%$ BSA. The RBCs were then used in the experiments of both hemagglutination activity (HA) and inhibition.

\section{Hemagglutination Assay (HA)}

The HA of serial twofold dilutions of test samples (reference value of HA was measured in the samples adjusted as $0.75 \mathrm{mg}$ protein $/ \mathrm{ml}$ buffer) were measured in $96 \mathrm{U}$-shaped plastic microtiter plates. Each well contained $25 \mu \mathrm{L} \quad \mathrm{RBC}$ suspensions and a $25 \mu \mathrm{L}$ sample diluted with Tris/NaCl. The wells were mixed by pipetting and then kept at $4^{\circ} \mathrm{C}$ for $2 \mathrm{~h}$. Agglutinated RBCs appeared to form a diffuse mat, whereas unagglutinated formed a clear dot on the bottom of the well. The HA was defined as the reciprocal of the maximum dilution of the test sample causing hemagglutination under the assay conditions (Hapner and Jermyn 1981; Ibrahim et al. 1984).

\section{Hemagglutination Inhibition Assay (HIA)}

The binding preference to sugars by lectins in the crude or isolated states was measured by competitive binding and measuring HA against sheep RBCs. The monosaccharides, D- (+) galactose, D- (+) - glucose (Sigma), D- (+) mannose (MP Biomedicals, Inc. Ohio, U.S.A); disaccharides, lactose, trehalose and D- (+) raffinose (Sigma), and the glycoproteins, laminarin, fetuin, and mucin (Sigma) were tested. Stock solutions of sugars and glycosubstances were prepared in TBS. For each inhibition test, serial 2-fold dilutions of $25 \mu \mathrm{L}$ of the inhibitors in $\mathrm{Tris} / \mathrm{NaCl}$ placed in microtitre plates were used. Subsequently, $25 \mu \mathrm{L}$ of the crude or isolated lectin preparations were added to each well, mixed by shaking, and incubated for at $37^{\circ} \mathrm{C}$ for $1 \mathrm{~h}$. Then 50 $\mu \mathrm{L}$ of $2 \%$ sheep RBCs suspension was added and the concentration of these sugars and glycosubstances required to result 50\% inhibition (IC50) of HA was determined (Goldstein and Hayes 1978).

\section{Divalent Cations Requirement For HA}

To examine the divalent cations requirements for the expression of HA, the method of Richards et al. (1988) was followed. Briefly, aliquots $(100 \mu \mathrm{L})$ 
of semi-lyophilized crude or isolated lectin preparations were dialyzed at $4^{\circ} \mathrm{C}$ for $24 \mathrm{~h}$ against $200 \mathrm{~mL}$ TBS (pH 7.0), with or without $20 \mathrm{mM}$ $\mathrm{Ca}^{2+}, 20 \mathrm{mM} \mathrm{Mg}^{2+}$, or $20 \mathrm{mM} \mathrm{Mn}{ }^{2+}$, or with 5 or $10 \mathrm{mM}$ EDTA at $\mathrm{pH} 7.0$ for $24 \mathrm{~h}$ with two changes of buffer. HA assays were then performed using sheep RBCs washed in the corresponding dialyzing buffer.

\section{RESULTS AND DISCUSSION}

\section{Isolation of Lectin}

Salting out of the proteins of the midgut homogenate by $30-80 \% \quad\left(\mathrm{NH}_{4}\right)_{2} \mathrm{SO}_{4}$ revealed strong HA against sheep RBCs (Fig. 1). When these proteins were subjected to ion exchange chromatography on DEAE-cellulose column and eluted with a linear gradient of $\mathrm{NaCl}(0.05-0.5$ M), two peaks indicated as "a" (factor I lectin) and "b" (factor II lectin) of protein fractions were obtained (Fig. 1). Among them, only the fraction $\mathrm{b}$ revealed HA. When this active fraction was pooled and further isolated by affinity chromatography using a CNBr-mannose-sepharose 6B column, HA was detected (Fig. 2). Therefore, this fraction seemed to contain the putative lectin, which was referred as Aelec. This lectin was specific mannose-bound lectin. The first cycle in Figure 2 showed the presence of a lectin of HA activity, which represented the humeral immune reaction of the midgut proteins of Ae. Aegypti.

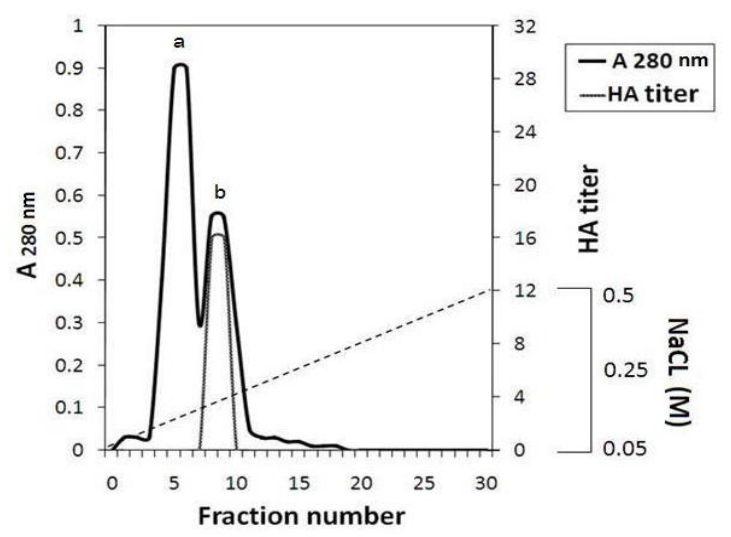

Figure 1 - Ion exchange chromatography of 30-80\% $\left(\mathrm{NH}_{4}\right)_{2} \mathrm{SO}_{4}$ fractionated proteins from Ae aegypti adult female midgut on a CM-cellulose column $(1.5 \times 30 \mathrm{~cm})$ equilibrated with TBS. The adsorbed proteins were eluted with a linear gradient of $0.05-0.5 \mathrm{M} \mathrm{NaCI}$ at a flow rate of $1.0 \mathrm{~mL} / \mathrm{min}$. Fractions of $3 \mathrm{~mL}$ were collected and assayed for Hemagglutination (HA).

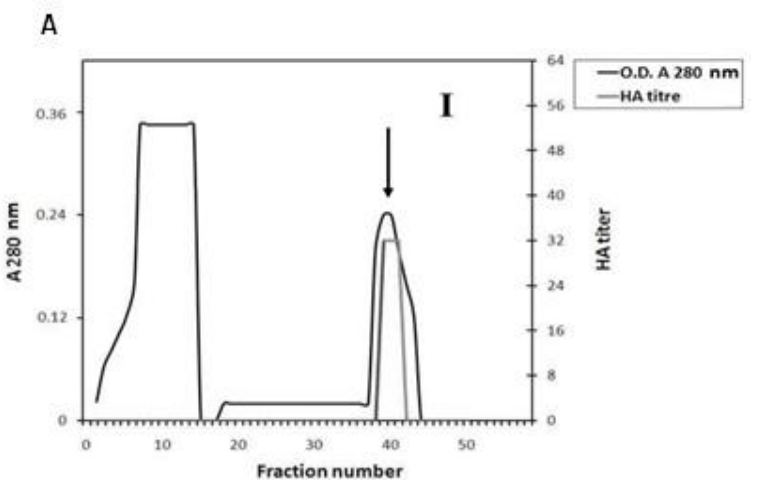

B

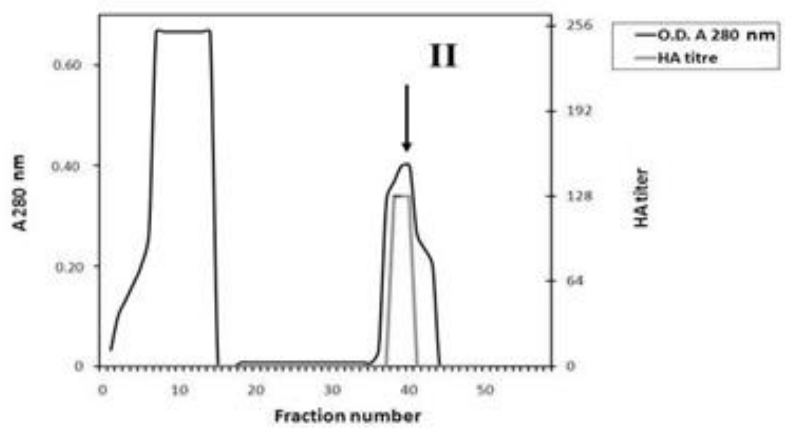

Figure 2 - Typical chromatograph showing affinity chromatography of lectins, contained in peaks I, II (a \& b) of proteins separated from Ae. aegypti adult female mid guts by DEAE-cellulose column, on mannoseCNBr-activated sepharose 6B . Lectins (bound components) were eluted with $0.3 \mathrm{M}$ mannose solution in TBS (indicated by arrows).

\section{Characterization of Lectin}

SDS/PAGE experiments (Fig. 3) showed that the isolated lectins consisted of two subunits of molecular weight 27.35 and $35.50 \mathrm{kDa}$ for the factors I and II lectins, respectively under reducing conditions. This indicated that the isolated lectin contained polypeptide chains linked by disulphide bridges.

Figure 4 revealed that the factor I and II lectins (Aelec) of Ae. aegypti midgut appeared as a single band with a $\mathrm{pI}$ value of 5.9, i.e., was in the acidic range. Similarly, the pI values of lectins isolated from different insect orders were in the acidic range (Stebbins and Hapner 1985; Minnick et al. 1986; Chen et al. 1993; Drif and Brehelin 1998; Ayaad 2008).

The HA of the crude lectin decreased by about $70 \%$ at $100^{\circ} \mathrm{C}$. Nevertheless, the purified lectin (Aelec) was heat-resistant at the same temperature. This showed that the crude lectin might contain other proteinaceous substances, which affected the HA (Drif and Brehelin 1994). 


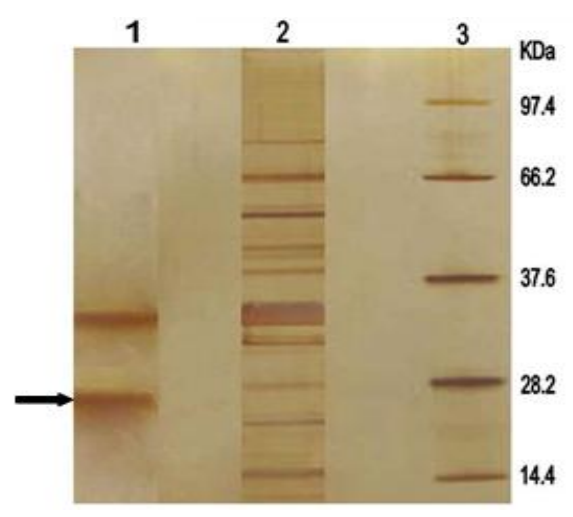

Figure 3 - SDS-PAGE of crude and purified lectins of Ae.aegypti adult female midgut. Lectins were loaded on $12 \%$ polyacrylamide gel under reducing conditions Gels were stained with silver nitrate. Lanes 1 and 2 show purified and crude (Aelec), respectively. Lane 3 represents the molecular weight $(\mathrm{kDa})$ of the standards. Arrow indicates the factor II lectin.

The isolated lectin (Aelec) and crude lectin exhibited higher affinity to agglutinate the sheep $\mathrm{RBCs}$ and human RBCs types $\mathrm{B}^{+}$and $\mathrm{O}^{+}$. The HA titers of the crude lectin against the sheep RBCs was identical to that of Aelec against the human RBCs type $\mathrm{B}^{+}$, while the HA titers of the isolated lectin against the sheep RBCs was identical to that of crude lectin against the human RBCs type $\mathrm{B}^{+}$ (Table 1).

Table 1 - Hemagglutination of crude and isolated lectins of midgut extract of Ae. aegypti against various erythrocytes.

\begin{tabular}{lll}
\hline Mammalian RBCs & HA titre \\
\cline { 2 - 3 } & Crude midgut lectin & Isolated midgut lectin \\
\hline Human: & 32 & 16 \\
$\mathrm{~A}^{+}$ & 128 & 64 \\
$\mathrm{~B}^{+}$ & 32 & 128 \\
$\mathrm{O}^{+}$ & 4 & 16 \\
Goat & 64 & 128 \\
Sheep & 4 & - \\
Guinea pig & 8 & 16 \\
Rat & 8 & 32 \\
Mouse & & \\
\hline
\end{tabular}

Data were obtained from a single experiment repeated three times. HA: haemagglutination

The HA against the remaining vertebrate RBCs showed mild titers ranging from 4 to 32 . No activity was shown towards the RBCs of Guinea pig for the isolated lectin.

When some sugars and glycosubstances were tested for the inhibition of HA of both the lectin states against sheep RBCs, variable degrees were obtained (Table 2). Among the tested sugars, D(+)-mannose inhibited the HA at a relatively lower concentration of 12.5 and $3.13 \mathrm{mM}$ for the crude and isolated lectin, respectively. The other sugars inhibited HA at a moderate or high concentration. For the tested glycosubstances (laminarin, fetuin, mucin), no inhibition was observed.

Table 2 - Hemagglutinaton inhibition of Ae. Aegypti crude mid gut extract and isolated lectins.

\begin{tabular}{lll}
\hline \multirow{2}{*}{ Sugar or glycosubstance } & \multicolumn{2}{c}{ Minimum concentration $\left(\mathrm{IC}_{50}\right)$ to HA } \\
\cline { 2 - 3 } & Crude midgut lectin & Isolate midgut lectin \\
\hline D-(+)-Galactose & $>200$ & 200 \\
D-(+)-Glucose & 50 & 12.5 \\
D-(+)-Mannose & 12.5 & 3.13 \\
Raffinose & 25 & 6.25 \\
Lactose & 200 & $>100$ \\
Trehalose & 200 & 200 \\
Laminarin & $0.3 \%$ & $0.03 \%$ \\
Fetuin & $0.1 \%$ & $0.1 \%$ \\
Mucin & $0.003 \%$ & $0.003 \%$ \\
\hline
\end{tabular}

Values $>200 \mathrm{mM}$ sugars or $>1 \%$ glycosubstance indicate that no inhibition of agglutination was recorded. Data were obtained from a single experiment repeated four times. Sheep RBCs are used as indicator. Minimum Concentration required for $50 \% \mathrm{HA}$ inhibition $\left(\mathrm{IC}_{50}\right)$. HA: haemagglutination.

The lectin in its isolated and crude states did not require $\mathrm{Ca}^{2+}$ for the expression of activity and other cations such as $\mathrm{Mn}^{2+}, \mathrm{Mg}^{2+}$. This was further confirmed by the dialysis against, or addition of, $500 \mathrm{mM}$ EDTA. These results indicated that Aelec was a $\mathrm{Ca}^{2+}$ - independent lectin.

Chen et al. (1993) reported that three lectins $\left(\mathrm{BDL}_{1}, \mathrm{BDL}_{2}\right.$ and $\left.\mathrm{BDL}_{3}\right)$ isolated from the haemolymph of the cockroach Blaberus discoidalis bound galactose but had different specificities for binding other sugars and for a range of vertebrate erythrocytes.

Most of the insect lectins isolated to date have presented two different subunits with disulfide linkage, e.g., the mosquitoes Anopheles stephensi (Chen and Billingsley 1999) and Ae. caspius (Ayaad 2008), coleopteran Allomyrina dichotoma (Umetsu et al. 1984), orthopterans Teleogryllus commodus (Hapner and Jermyn 1981) and Melanoplus sanguinipes (Stebbins and Hapner 1985), and dictyopteran Blaberus discoidalis (Chen et al. 1993). In comparison, the lectin (ACL) isolated from the whole body homogenate of Ae. caspius, using SDS/PAGE under reducing 
conditions, consisted of two bands of 32 and 34 kDa (Ayaad 2008).

Similarly, heat-resistant lectins have also been reported in the coleopteran Leptinotarsa decemlineata (Minnick et al. 1986) and dipteran Ae. caspius (Ayaad 2008). In contrast, lectins isolated from the orthopteran Telogryllus commodus (Hapner and Jermyn 1981), Melanoplus sanguinipes (Stebbins and Hapner 1985) and Schistocerca gregaria (Ayaad 2004; Dorrah et al. 2009) and the dsipteran Glossina fuscipes (Ingram and Molyneux 1990) were heatlabile, as the HA decreased with the increase in temperature.

In other dipterans, the same specificity for sheep RBCs was observed (Komano et al. 1980; Chen and Billingsley 1999; Ayaad 2008). On the other hand, the lectins of other insects show variable preferences to RBCs of different vertebrates (Ingram and Molyneux 1990).

These results were similar to some extent to those of Chen et al. (1993). They found that the purified lectin BDL1 from the haemolymph of the cockroach $B$. discoidalis was specifically inhibited by D-(+)-glucose, D-(+)-mannose and N-acetyl-Dmannosamine. On the other hand, Ayaad (2008) found that the isolated lectin (ACL) from the whole body homogenate of Ae. caspius was inhibited at a high extent $\left(\mathrm{IC}_{50}=12 \mathrm{mM}\right)$ by Nacetyl-D-galactosamine. Volf et al. (2002) and McGreal et al. (2004) reported that carbohydrate binding specificity was important in recognition of carbohydrates on pathogen surfaces, which were crucial in determining the capability of the insect as a vector in pathogen transmission. In this respect, there is growing evidence that they can mediate the infection of pathogens to their insect vectors, and their disruption can affect subsequent establishment of the pathogen within the vector. This property was recorded for other insect lectins, e.g., B. discoidalis (Chen et al. 1993), G. fuscipes (Ingram and Molyneux 1990), Oecophylla smaragdina (Hassan and Absar 1995), and Phlebotomus duboscqi (Volf et al. 2002), Ae. caspius (Ayaad 2008). In contrast, the lectins of Schistocerca gregaria (Ayaad 2004) and Spodoptera exigua (Pendland and Boucias 1986) were $\mathrm{Ca}^{2+}$ - dependent. Calcium is not required for lectin binding to the sugar, but protects it from proteinase digestion (Yu and Ma 2006).

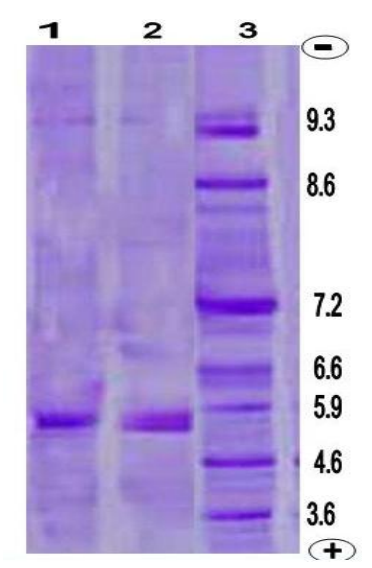

Figure 4 - Iso-electric focusing point (IEF) of Aedes. aegypti purified mid gut lectin using SDS-PAGE. Lanes 1 and 2 showed PI of purified fractions I and II obtained from affinity chromatography column. Lane 3, standards calibration kits of Sigma. CBB staining.

\section{ACKNOWLEDGEMENT}

This research project was supported by a grant from the "Research Center of the Female Scientific and Medical Colleges", Deanship of Scientific Research, King Saud University.

\section{REFERENCES}

Abdoon AM, Ibrahim AA. Mosquito breeding habitats in Tihama lowlands of Asir region, Kingdom of Saudi Arabia. Proc. of 3rd Confer. Appl Entomol. 2005: 1-18.

Ahmed AM, Abdel-Mageed AAM, AL-Qahtaney HM. A Novel Mosquitocidal Bacterium as a Biocontrol Agent in Saudi Arabia: I- a promising larvicide against Aedes caspius mosquito. Pakistan J Zool. 2014; 46(1): 191-201.

Ahmed AM, Shaalan EA, Aboul-Soud MAM, Tripet F, AL-Khedhairy AA. Mosquito vectors survey in ALAhsaa district, eastern region, Kingdom of Saudi Arabia. J Insect Science. 2011; 11(176): 1-11.

AL-Khreji MA. Survey and distribution of mosquito species (Diptera: Culicidae) and description of its habitat in Riyadh district, Kingdom of Saudi Arabia. M.Sc. Thesis, King Saud University, Kingdom of Saudi Arabia. 2005.

Ayaad TH, Dorrah MA, Mohamed AA, Bassal TTM. Specificity and developmental changes of hemagglutination activity of serum of the desert locust Schistocerca gregaria (Orthoptera: Acridadae). J Orthopt Res. 2009; 18: 51-56. 
Ayaad TH. Isolation and partial characterization of $\mathrm{Ca}^{2+}$-independent lectin from Aedes caspius (Diptera: Culicidae). Efflatounia. 2008; 8: 17-28.

Ayaad TH. Isolation, characterization, and N-terminal amino acid sequence of lectin from plasma of Schistocerca gregaria. Efflatounia. 2004; 4: 9-22.

Ayyub M, Khazendar AM, Lubbad EH, Barlas S, Alfi AY, AL-Ukayli S. Characteristics of dengue fever in a large public hospital, Jeddah, Saudi Arabia. J Ayub Med Coll Abbottabad. 2006; 18(2): 9-13.

Bradford MM. A rapid and sensitive method for the quantitation of microgram quantities of protein utilizing the Principal of Protein-dye binding. Analyt Biochem. 1976; 72: 248-254.

Chen C, Billingsley P. Detection and characterization of a mannan-binding lectin from mosquito, Anopheles stephensi (Liston). Eur J Biochem. 1999; 263: 360366.

Chen C, Ratcliffe NA, Rowley AF. Detection, isolation and characterization of multiple lectins from the hemolymph of the cockroach, Blaberus Ddiscoidalis. Biochem J. 1993; 294: 181-190.

Dodd RB, Drickamer K. Lectin-like proteins in model organisms: implications for evolution of carbohydrate-binding activity. Glycobiol. 2001; 11: 71R-79R.

Dorrah MA, Ayaad TH, Mohamed AA, Bassal TTM. Isolation and characterization of multiple-lectins from serum of the desert locust Schistocerca gregaria (Orthoptera: Acrididae). J Orthop Res. 2009; 18: 103 112.

Fakeeh M, Zaki A. Dengue in Jeddah, Saudi Arabia, 1994-2002. Dengue Bulletin. 2003; 27: 13-18.

Gillespie JP, Kanost M, Trenczek T. Biological mediators of insect immunity. Anпu Rev Entomol. 1997; 42: 611-643.

Goldstein IJ, Hayes CE. Carbohydrate-binding Proteins of Plants and Animals. In: Tipson, R. S., Horton, D. (Eds), Advances in Carbohydrate Chemistry and Biochemistry, Academic Press, New York, 1978; 127-340.

Gubler DJ. Resurgent vector-borne diseases as a global health problem. Emerg Infect Dis. 1998; 4: 442-450.

Hapner KD, Jermyn MA. Hemagglutinin activity in the hemolymph of Teleogryllus comodus (Walker). Insect Biochem. 1981; 11: 287-295.

Hassan P, Absar N. Isolation, purification and characterization of three lectins from ant eggs (Oecophylla smaragdina Fabr.). Carbohydrate Res. 1995; 273: 63-70.

Ibrahim EAR, Ingram GA, Moulyneux DH. Haemagglutinins and parasite agglutinins in haemolymph and gut of Glossina. Tropenmed Parasitol. 1984; 35: 151-156.
Ingram GA, Moulyneux DH. Lectins (haemagglutinins) in the haemolymph of Glossina fuscipes: isolation, partial characterization, selected physico-chemical properties and carbohydrate-binding specificities. Insect Biochem. 1990; 20: 13-27.

Khan NA, Azhar EI, EL-Fiky S, Madani HH, Abuljadial MA, Ashshi AM, et al. Clinical profile and outcome of hospitalized patients during first outbreak of dengue in Makkah, Saudi Arabia. Acta Trop. 2008; 105(1): 39-44.

Komano H, Mizuno D, Natori S. Isolation of lectin induced in the hemolymph of Sarcophaga peregrina larvae on injury. J Biol Chem. 1980; 255: 2919-2924.

Kurata S, Ariki S, Kawabata S. Recognition of pathogens and activation of immune responses in Drosophila and horseshoe crab innate immunity. Immunobiol. 2006; 211: 237-249.

Lis H, Sharon N. Lectins: carbohydrate-specific proteins that mediate cellular recognition. Chem Rev. 1998; 98: 637-674.

Mattingly PF, Knight KL. The mosquito of Arabia. Bull Brit Mus Nat Hist. (Ent.), 1956; 4: 89-141.

McGreal EP, Martinez-Pomares L, Gordon S. Divergent roles for C-type lectins expressed by cells of the innate immune system. Mol Immunol. 2004; 41: 1109-1121.

Miarons PB , Escudero MF. Lectins from tropical sponges: Purification and characterization of lectins from genus Aplysina. J Biol Chem. 2000; 275: 29283 29289.

Minnick ME, Rupp RA, Spence KD. A bacterialinduced lectin which triggers hemocyte coagulation in Manduca sexta. Biochem Biophys Res Comm. 1986; 137: 729-736.

Mohamed HA, Ingram GA. Effects of physicochemical treatments on hemagglutination activity of Anopheles gambiae hemolymph and midgut extract. Med Vet Entomol. 1994; 8: 8-14.

Pendland JC, Boucias DG. Characteristics of a galactose-binding hemagglutinin (lectin) from hemolymph of Spodoptera exigua larvae. Develop Comp Immunol. 1986; 10: 477-487.

Rabilloud T. Mechanisms of Protein Silver Staining in Polyacrylamide gels: A 10-year Synthesis. Electrophoresis. 1990; 11: 785-794.

Richards EH, Ratcliffe NA, Renwrantz LR. Isolation and characterization of a serum lectin from the giant stick insect Extatosoma tiaratum. Insect Biochem. 1988; 161: 43-54.

Stebbins MR, Hapner KD. Preparation and properties of haemagglutinin from haemolymph of Acrididae (grasshoppers). Insect Biochem. 1985; 15: 451-462.

Umetsu K, Kosaka S, Suzuki T. Purification and characterization of a lectin from the beetle Allomyrina dichotoma. J Biochem. (Tokyo), 1984; 95: 239-246. 
Vasta GR, Ahmed H, Tasumi S, Odom EW, Saito K. Biological Roles of Lectins in Innate Immunity: Molecular and structural basis for diversity in self/non-self recognition. Curr Top Innate Immun. 2007; 598: 389-406.

Volf P, Skarupova S, Man P. Characterization of the lectin from females of Phlebotomus duboscqi sand flies. Eur J Biochem. 2002; 269: 6294-6301.

$\mathrm{Yu}$ XO, Ma Y. Calcium is not required for Immulectin2 , but protects the protein from proteinase digestion. Insect Biochem Mol Biol. 2006; 36: 505-516.

Received: May 20, 2015; Accepted: July 15, 2015. 